\title{
Electrical properties of aluminum contacts deposited by DC sputtering method for photovoltaic applications
}

\author{
Ewelina Krawczak ${ }^{1, *}$, and Stawomir Gułkowski ${ }^{1}$ \\ ${ }^{1}$ Faculty of Environmental Engineering, Lublin University of Technology, Nadbystrzycka 38, 20-618 Lublin, Poland
}

\begin{abstract}
The use of aluminum contacts is common in the process of silicon solar cells production because of low contact resistivity. It has also a great importance in thin film technology for photovoltaics, especially in copper-indium-gallium-diselenide (CIGS) devices. The final stage of CIGS cell production is the top contact deposition of high conductivity layer for lateral current collection. Such material has to be highly optically transparent as well. In order to make a contact, metal is deposited onto TCO layer with minimum shadowing to allow as much light as possible into device. The metal grid contact is being made by deposition of few microns of aluminum. The resistivity of the deposited material as well as resistance between the metal grid and TCO layer plays a great role in high quality solar cell production. This paper presents the results of four point probe conductivity analysis of $\mathrm{Al}$ thin films deposited by direct current (DC) magnetron sputtering method. Influence of technological parameters of the Al deposition process on sheet resistance of deposited layers has been showed. In order to obtain the lowest resistivity of the thin contact layer, optimal set of sputtering parameters, i.e. power applied, deposition time and deposition pressure was found. The resistivity of the contact between two adjacent Al metal fingers deposited onto transparent conductive Al-doped zinc oxide film has been also examined.
\end{abstract}

\section{Introduction}

Recently, materials for thin film solar cells are the subject of researcher interest. Their good technological parameters and application in low-cost, high-rate semiconductors with a thickness of few microns are main objectives to be achieved. Solar cells based on chalcopyrite materials, such as $\mathrm{Cu}(\mathrm{InGa}) \mathrm{Se}_{2}$ (CIGS), achieved the highest conversion efficiency of up to $22.4 \%$ [1]. Direct band gap, high absorption coefficient for solar radiation and inherent $p$-type conductivity make CIGS structure one of the most promising absorber material forsolar cell application. Despite of this, the optimization process need to be implemented for improving homogeneity in large-scale manufactured cells, increasing efficiency and reducing cost of production process. The basic CIS/CIGS cell structure is deposited on soda lime glass, but can be also obtained on flexible substrates made of metal [2], ceramic [3], ultrathin glass [4] or thin stainless steel [5]. The model is based on $\mathrm{Cu}(\mathrm{InGa}) \mathrm{Se}_{2} / \mathrm{CdS}$ junction and Mo back contact. The core of the CIGS solar cell is CIGS p-type absorber layer with the large variety of deposition possibilities, such as magnetron sputtering method [6], electrodeposition [7,8], co-evaporation [9], lowtemperature pulsed electron deposition (LTPED) [10,11] and sputtering with post-selenization [12-13]). The top layers (front contact) are made of transparent conductive oxide (TCO) with high-conductivity. TCO materials are mainly based on tin oxide $\left(\mathrm{SnO}_{2}\right)$, indium tin oxide $\left(\mathrm{In}_{2} \mathrm{O}_{3}\right)$, zinc oxide $(\mathrm{ZnO})$ or theirs combinations, but the most widely applied is indium tin oxide (ITO). This material is characterized by good optical and electrical properties, but its quantity is limited, because of uniqueness and cost of indium element. Zinc oxide $(\mathrm{ZnO})$ and $\mathrm{ZnO}$ structures doped with the third group element, such as $\mathrm{B}, \mathrm{Ga}$, In, $\mathrm{Al}$ can be appropriate replacement of ITO layers as a front electrode [14]. The transparent films can be made by use of variety techniques, such as magnetron sputtering deposition (RF or DC mode), chemical vapour deposition, sol-gel deposition, spray coating, pulsed laser deposition (PLD), atomic layer deposition (ALD) or metalorganic chemical vapor deposition technique (MOCVD) [15-19]. The above mentioned layers are characterized by the high transmittance, wide band gap and low resistivity [20-21]. Completion of the CIGS structure is current-collecting grid, which can be made of aluminum.

This paper presents the magnetron sputtering process optimization in terms of aluminum deposition on thin film transparent conductive layer as a top contact for photovoltaic applications. Influence of the process parameters such as power, pressure and deposition time was found. Sheet resistance of the films deposited under various technological parameters were measured. Dependency of the TCO layer conductivity on the resistance between adjacent fingers was also examined.

Corresponding author: e.krawczak@pollub.pl 


\section{Materials and methods}

The transparent conductive $\mathrm{Al}$ doped $\mathrm{ZnO}$ films and aluminum contacts were deposited onto $1 \mathrm{~mm}$ thick soda lime glass slides by using Alliance Concept AC450 magnetron sputtering system. Firstly, the ZnO:Al layer was deposited and then $\mathrm{Al}$ metal grid was obtained by using glass mask on the top of Al doped Zinc Oxide film. The glass substrates were ultrasonically and chemically cleaned with acetone, ethanol and dried with nitrogen.

After the cleaning process, samples were immediately loaded inside the magnetron deposition chamber under the target directly. The $10.16 \mathrm{~cm}$ (4 inches) in diameter and $6 \mathrm{~mm}$ thick targets with purity of $99.999 \%$ were used. The RF power was applied to $\mathrm{ZnO}: \mathrm{Al}$ ceramic cathode made by $98 \%$ wt. $\% \mathrm{ZnO}$ and 2 wt. $\% \mathrm{Al}$ and the DC power to aluminum target. The distance between the target and the substrate was fixed at $90 \mathrm{~mm}$. The films were obtained at room temperature in Ar atmosphere. Overheating of the substrate holder was avoided due to water cooling system. After mounting the substrates, the sputtering chamber was evacuated to the base pressure equals $1.0 \times 10^{-2} \mathrm{~Pa}$ in order to carry out the presputtering process and remove undesired impurities from the target surface.

The Al doped $\mathrm{ZnO}$ films were obtained with optimal parameters, such as power of $290 \mathrm{~W}$, working pressure of $0.26 \mathrm{~Pa}$ and deposition time $-45 \mathrm{~min}$. In order to find optimal technological parameters, several series of aluminum top contact layers were deposited. In each series, technological parameters as discharge power, deposition time and deposition pressure were varied during the deposition process.

Sputtering power density was ranged from $0.75 \mathrm{~W} / \mathrm{cm}^{2}$ to $1.25 \mathrm{~W} / \mathrm{cm}^{2}$.

Deposition time was fixed at 15, 30, $45 \mathrm{~min}$ and the working pressure varied from 0.2 to $1.57 \mathrm{~Pa}$. The sheet resistance of each layer and the metal - TCO contact was determined at room temperature using RM3000+ four point probe equipment of Jandel Engineering Limited, shown in Fig. 1.

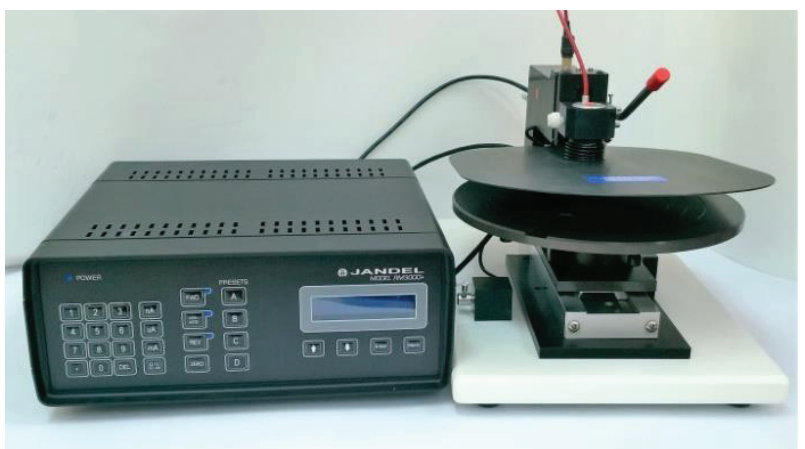

Fig. 1. RM3000+ four point probe equipment of Jandel Engineering Limited.

The optimal parameters of $\mathrm{Al}$ layers were chosen to deposition as a contact fingers on the top of $\mathrm{ZnO}: \mathrm{Al}$ film. Then the resistances $\left(R_{1}, R_{2}\right)$ between adjacent metallic contacts were measured by using multimeter, which is shown in Fig. 2.

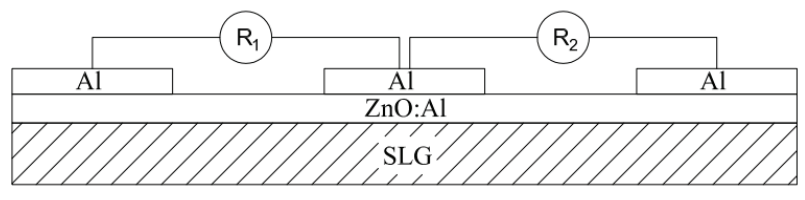

Fig. 2. A schematic representation of the prepared structure with measurement points.

\section{Results and discussion}

Four probe method were used to measure electrical parameters of the prepared samples. Fig. 3 shows the comparison of sheet resistance (Rs) dependency on deposition time at different powers of $60 \mathrm{~W}, 80 \mathrm{~W}$ and $100 \mathrm{~W}$ applied to the aluminum cathode. The working pressure was kept constant at $1.57 \mathrm{~Pa}$.

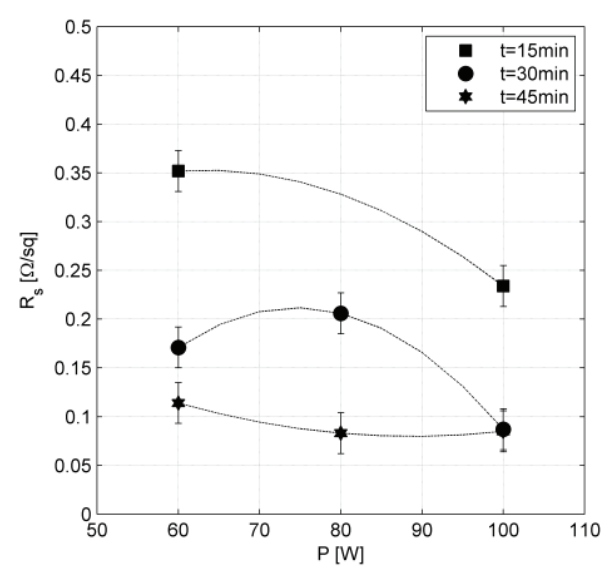

Fig. 3. Sheet resistance dependency on the deposition time at different deposition power applied to the $\mathrm{Al}$ cathode.

In each case the sheet resistance was found to decrease with increasing deposition time. This can be explained by the fact that resistance of the layer decreases with the increase of its thickness that depends on the time of deposition as it was reported in [22]. As it can be seen in Fig. 3 for power equals $60 \mathrm{~W}$ the sheet resistance decreases rapidly from $0.35 \Omega /$ sq to about $0.1 \Omega /$ sq in 30 minutes of the deposition process. In case of higher power this drop is even faster. For power equals $100 \mathrm{~W}$ the level of sheet resistance value of about $0.1 \Omega /$ sq was achieved after less than 30 minutes of the deposition. Further increase of the deposition time does not lead to better conductivity of the layer.

Fig. 4 compares the sheet resistance of aluminum thin films prepared at two different deposition powers and deposition times. The power varied from $60 \mathrm{~W}$ to 100 W. Fig. 4 depicts that sheet resistance of the deposited layer is more sensitive to the power applied in the case of the values of the deposition times lower than $30 \mathrm{~min}$. In case of higher values of the deposition time (i.e. $45 \mathrm{~min}$ ) the influence of the deposition power on sheet resistance can be negligible. From the foregoing discussion the conclusion is that the lowest value of sheet resistance can be obtained for deposition time and power equal to $30 \mathrm{~min}$ and $100 \mathrm{~W}$ respectively. Lower value of power applied $(80 \mathrm{~W})$ demands longer duration 
of deposition process (45 min) to obtain optimal conductivity of the contact layer.

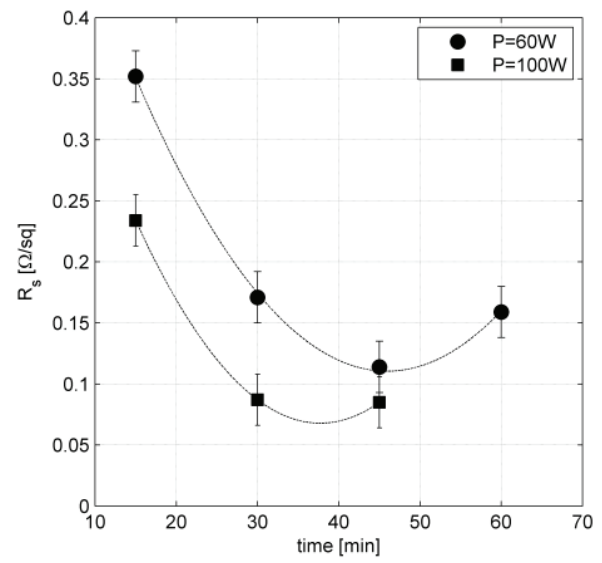

Fig. 4. Sheet resistance dependency on the deposition power at different deposition times.

For further optimization of the deposition process technological parameters dependence of the sheet resistance on the deposition pressure has been investigated. Four samples of the thin films deposited at power of $80 \mathrm{~W}$ and time equals $45 \mathrm{~min}$ have been prepared at working pressure which varied from 0.3 to 1.2 Pa. From Fig. 5, a correlation of the resistance on the deposition pressure was not observed.

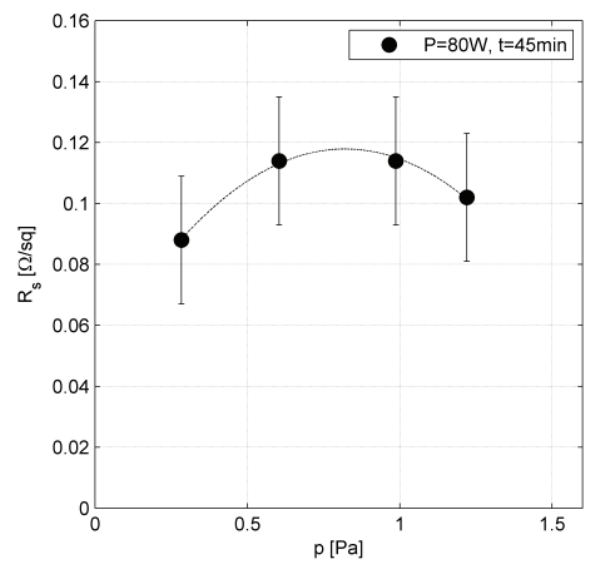

Fig. 5. Sheet resistance as a function of the deposition pressure. The deposition power and time were equal to $45 \mathrm{~min}$ and $80 \mathrm{~W}$ respectively.

Sheet resistance of the given films varied from $0.09 \Omega / \mathrm{sq}$ to $0.12 \Omega / \mathrm{sq}$ in this case. However, it can be assumed that sheet resistance decrease with decreasing of the pressure and better conductivity of the film should be obtained at the deposition pressure not greater than 0.4 $\mathrm{Pa}$.

From Figs. 3 - 5, the optimal parameters of the deposition have been established in order to obtain Al film of the highest conductivity. Optimal parameters were chosen as follows: deposition power, $100 \mathrm{~W}$; deposition time, $30 \mathrm{~min}$ and pressure, $0.4 \mathrm{~Pa}$. However, the top contact of the CIGS solar cells consists of thin layer of transparent conductive oxide (i.e. zinc oxide) and metallic fingers on the top of the layer.

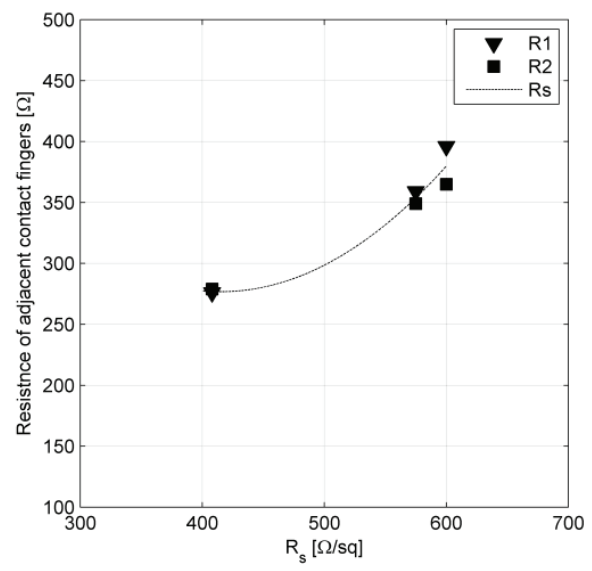

Fig. 6. Correlation between sheet resistance of the transparent layer and resistance of adjacent $\mathrm{Al}$ contact grids.

In order to examine the influence of the particular layers on the conductivity of the complete structure, the samples were prepared according to the scheme presented in Fig. 2. Figure 6 shows the results of resistance measurements between two adjacent aluminum fingers deposited on the top of the Al-doped zinc oxide film. It can be clearly seen that this resistance strongly depends on the quality of the transparent oxide and increases with the increase of the sheet resistance of the $\mathrm{ZnO} / \mathrm{Al}$ film measured by four point probe method.

\section{Conclusions}

Influence of the $\mathrm{Al}$ deposition technological parameters on the sheet resistance of the Al films were studied. These parameters were as follows: deposition power, deposition time and pressure during the process. Metal layers were deposited on the soda lime glass (SLG). Sheet resistance was measured with the use of four point probe method. It was found that the sheet resistance decreases with the increase of the deposition time as well as power applied. After about 30 minutes of the deposition with use of power equal to $100 \mathrm{~W}$, sheet resistance was found around $0.1 \Omega / \square$ which is small enough value in solar cell applications What is more, after this time, significant changes of the sheet resistance with power applied was not noticed. In the second stage of work Al metal were deposited onto TCO in order to measure the influence of the TCO layer on the conductivity of the structure. It was found that conductivity of the contact strongly depend on the conductivity of the transparent oxide. In the conclusion, optimized parameters of deposition process were found to obtain the best quality aluminum front-contact for CIGS solar cells.

\section{References}

1. P. Jackson, R. Wuerz. D. Hariskos, E. Lotter, W. Witte, M. Powalla, Phys. Status Solidi RRL, 10 (2016) 
2. T. Yagioka, T. Nakada, Appl. Phys. Express, 2, 072201 (2009)

3. S. Ishizuka A. Yamada, K. Matsubara, P. Fons, K. Sakurai, S. Niki, Curr. Appl. Phys. 10 (2010)

4. A. Gerthoffera, C. Poulainb, F. Rouxa, F. Emieuxa, L. Greneta, S. Perrauda, Sol. Energ. Mat. Sol. C 166 (2017)

5. W.-S. Liu, H.-C. Hua, N.-W. Pu, S.-C. Liang, J. Alloy Compd. 631 (2015)

6. S. Gułkowski, E. Krawczak, J. Olchowik, Proc. of $31^{\text {st }}$ Eur. Photovoltaic Solar Energy Conf. and Exhibition (2015)

7. C. Adel, B.M. Fethi, B. Brahim, Optik 127 (2016)

8. M. Ganchev, J. Kois, M. Kaelin, S. Bereznev, E. Tzvetkova, O. Volobujeva, N. Stratieva, A. Tiwari, Thin Solid Films 511 - 512 (2006)

9. Repins, M. A. Contreras, B. Egaas, C. DeHart, J. Scharf, C. L. Perkins, B. To, R. Noufi, Prog. Photovolt. 16 (2008)

10. S. Rampino, N. Armani, F. Bissoli, M. Bronzoni, D. Calestani, M. Calicchio, N. Delmonte, E. Gilioli, E. Gombia, R. Mosca, L. Nasi, F. Pattini, A. Zappettini, M. Mazzer, Appl. Phys. Lett. 101, 132107 (2012)

11. N. Cavallari, F. Pattini, S. Rampino, F.Annoni, M. Barozzi, M. Bronzoni, E. Gilioli, E. Gombia, C. Maragliano, M. Mazzer, G. Pepponi, G. Spaggiari, R. Fornari, Appl. Surf. Sci. 412 (2017)

12. X. Peng, M. Zhao, D. Zhuang, L.Guo, L. Ouyang, R. Sun, L. Zhang,Y. Wei, S. Zhan, X. Lv, Y. Wu, G. Ren, J. Alloy Compd. 710 (2017)

13. J.-K. Sim, S.-K. Lee, J.-S. Kim, K.-U. Jeong, H.-K. Ahn, C.-R. Lee, Appl. Surf. Sci. 389 (2016)

14. J.-H. Cha, S.-M. Kwon, J.A. Bae, S.H. Yang, C.-W. Jeon, J. Alloy Compd. 708 (2017)

15. S. Kuprenaite, A. Abrutis, V. Kubilius, T. Murauskas, Z. Saltyte, V. Plausinaitiene, Thin Solid Films 559 (2016)

16. T. Schuler, T. Krajewski, I. Grobelsek, M.A. Aegerter, Thin Solid Films 502 (2006)

17. S. Kuprenaite, T. Murauskas, A. Abrutis, V. Kubilius, Z. Saltyte, V. Plausinaitiene, Surf. Coat. Tech. 599 (2016)

18. C.G. Granqvist, Sol. Energy Mat. Sol. C 91 (2007)

19. E. Guziewicz, I.A. Kowalik, M. Godlewski, K. Kopalko, V. Osinniy, A. Wójcik, S. Yatsunenko, E. Łusakowska, W. Paszkowicz, M. Guziewicz, Jpn. J. Appl. Phys. 103, 033515 (2008)

20. J. Yoo, J. Lee, S. Kim, K. Yoon, I.J. Park, S.K. Dhungel, B. Karunagaran, D. Mangalaraj, J. Yi, Thin Solid Films 480-481 (2005)

21. B.G. Choi, I.H. Kim, D.H. Kim, K.S. Lee, T.S. Lee, B. Cheong, Y.-J. Baik, W.M. Kim, J. Eur. Ceram. Soc. 25 (2005)

22. A. Zdyb, E. Krawczak , P. Lichograj, Opt. Appl. 46 (2016) 